\section{REFERENCES}

1. Schocken DD, Arrieta MI, Leaverton PE, et al. Prevalence and mortality rate of congestive heart failure in the United States. J Am Coll Cardiol 1991;20:301-6.

2. Fonorow GC, Chelimsky-Fallick C, Stevenson LW, et al. Effect of direct vasodilation vs angiotensin-converting enzyme inhibition on mortality in advanced heart failure: the Hy-C trial. J Am Coll Cardiol 1992;19:842-50.

3. Magovern GJ Sr. Paced skeletal muscle for dynamic cardiomyoplasty. Ann Thorac Surg 1995;60:1153-4.

4. Thakur RK, Chow LH, Geraldine GM, et al. Latissimus dorsi dynamic cardiomyoplasty: role of combined ICD implantation. J Card Surg 1995;10:295-7.
5. Podrid PJ, Fogel RI, Fuchs TT. Ventricular arrhythmia in congestive heart failure. Am J Cardiol 1992;69:82G-96G.

6. Moreira LF, Stolf NA, Bocchi EA, et al. Clinical and left ventricular function outcomes up to five years after dynamic cardiomyoplasty. J Thorac Cardiovasc Surg 1995;109:353-63.

7. Carpentier A, Chachques JD, Acar C. Dynamic cardiomyoplasty at seven years. J Thorac Cardiovasc Surg 1993;106:42-54.

8. Chekanov VS, Krakovsky AA, Buslenko NS, et al. Cardiomyoplasty: review of early and late results. Vasc Surg 1994;28: 481-9.

9. Akhtar M, Avitall B, Jazayeri M, et al. Role of implantable cardioverter defibrillator therapy in the management of highrisk patients. Circulation 1992;85(suppl 1):1-131.

\title{
CALCIFIED PEDICLED THROMBUS IN THE LEFT VENTRICLE: THE FINE ART OF NATURE
}

\author{
Carlos Morales, MD, ${ }^{\mathrm{a}}$ José M. Bernal, MD, ${ }^{\mathrm{a}}$ José M. Rabasa, MD, ${ }^{\mathrm{a}}$ Francisco Gutiérrez, MD, ${ }^{\mathrm{a}}$ Fernando Val, MD, \\ and José M. Revuelta, MD, ${ }^{a}$ Santander, Spain
}

Intracavitary cardiac thrombi are infrequent and usually found in patients with concomitant heart disease. These thrombi have a rubbery or malleable consistency, and calcification is rare. ${ }^{1}$ Cases of calcified ball thrombus of the fixed type (attached to the atrial wall or septum) have occasionally been published. To our knowledge no case of calcified pedicled thrombus in the left ventricle has been previously reported.

A 46-year-old man with a recent history of thromboangiitis obliterans and characteristic nodules on the legs was found to have a calcified cardiac image on a chest roentgenogram while undergoing a work-up for a 6-month history of nonspecific discomfort and generalized asthenia. He was a heavy smoker with moderately elevated serum cholesterol levels. He had no symptoms of cardiac disease. Doppler echocardiography showed enlargement of the left ventricle with a decreased ejection fraction and apical akinesia. An elongated mass was fixed to the apex of the left ventricle, moving through the cavity, but no mitral valve abnormality was observed. Cardiac catheterization showed two-vessel disease with significant obstructions in the anterior descending and right coronary arter-

From the Departments of Cardiovascular Surgery a and Anatomic Pathology, ${ }^{\mathrm{b}}$ Hospital Universitario Valdecilla, Universidad de Cantabria, Santander, Spain.

Received for publication Feb. 10, 1997; accepted for publication Feb. 25, 1997.

Address for reprints: José M. Bernal, MD, Department of Cardiovascular Surgery, Hospital Universitario Valdecilla, E-39008 Santander, Spain.

J Thorac Cardiovasc Surg 1997;114:491-2

Copyright (c) 1997 by Mosby-Year Book, Inc.

$0022-5223 / 97 \$ 5.00+0 \quad \mathbf{1 2 / 5 4 / 8 1 4 7 8}$ ies. The left ventriculogram showed apical akinesia in the area in which a pedicled and elongated mass originated (Fig. 1). The operation was performed with the use of standard cardiopulmonary bypass.

With the heart arrested with retrograde cardioplegia, the left ventricle was opened through the apex and an elongated mass attached to the apical endocardium by thin trabeculae was removed. The mass had a smooth, hard surface and its color was pearly. The apical opening in the left ventricle was repaired with a round Teflon patch and autologous pericardium implanted endocardially. Coronary artery bypass grafting was done concomitantly. The resected mass was ovoid and measured $5 \mathrm{~cm}$ in length by $1.8 \mathrm{~cm}$ in diameter in the central area (proximal

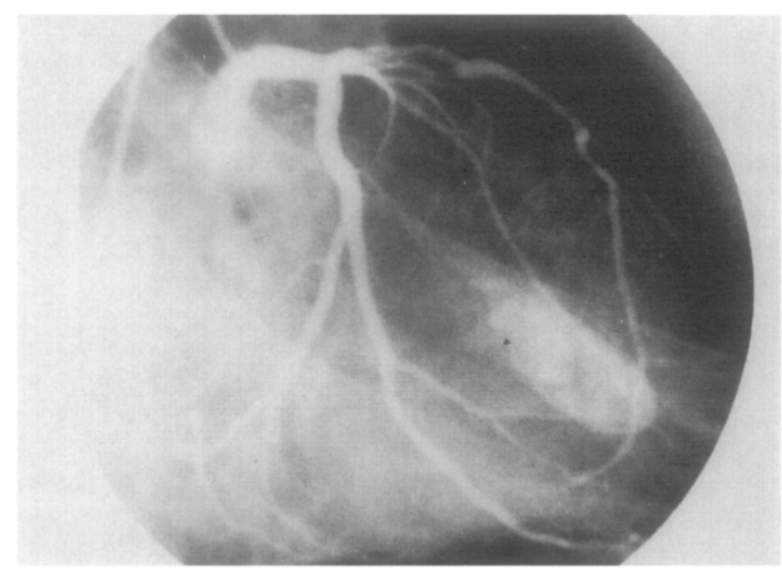

Fig. 1. Left ventriculogram showing the calcified pedicled mass attached to the apex. A significant lesion is present in the proximal anterior descending artery. 


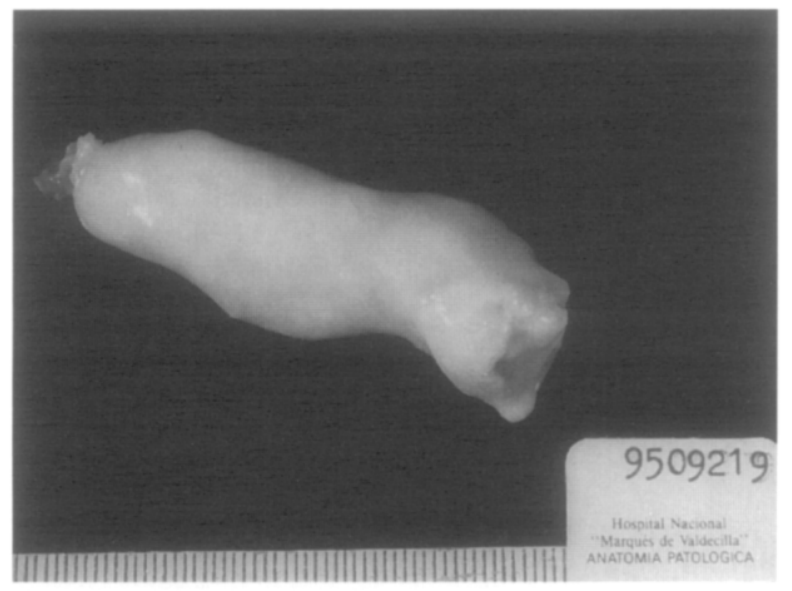

Fig. 2. Gross view of the calcified thrombus and the trabeculae attached to the endocardium.

and distal diameters 1.1 and $1.0 \mathrm{~cm}$, respectively) (Fig. 2). The gross cross-sectional view of the lesion demonstrated a thrombus, disorganized at the center with granulomas of cholesterol, and extensive calcification and ossification with plexiform trabeculae at the periphery. The surface was covered with endocardium with large areas of fibrosis. Histologic examination of the mass showed the typical features of a calcified thrombus. Postoperative recovery was uneventful. At present, 3 months after operation, the patient is free of symptoms.

Calcified atrial ball thrombi are rare. They are usually found in the setting of mitral valve disease or atrial fibrillation, and more frequently in the left atrium. In a review by Wrisley and coworkers ${ }^{2}$ in 1991, 11 cases of left atrial ball thrombus published in English since 1976 were collected. In these patients, syncope, paroxysmal dyspnea, peripheral or central embolism, and sudden death were common presenting symptoms. Cases of calcified throm- bus in the right atrium have been reported as a rare complication of long-term parenteral nutrition ${ }^{3}$ or myxomas. ${ }^{4}$ Although calcification of thrombi is easily detectable by conventional chest $x$-ray films, definitive diagnosis is made by ultrasonography.

So far as we are aware, this is the first report of a calcified thrombus in the left ventricle. Although coronary artery disease with akinesia of the apex of the left ventricle (the site at which the thrombus was fixed) was involved in this case, the process of thrombus formation is unclear and the histopathologic examination was unrevealing. Myocardial infarction could not be demonstrated. The thrombus was attached to the left ventricular wall by thin trabeculae, which were similar to those of the endocardium. Although the pedunculated thrombus appeared to be firmly attached according to the ultrasonogram and the risk of detachment and escape into the general circulation seemed low, in the absence of significant coronary artery disease surgical removal of the mass was clearly indicated. Because a chest roentgenogram had not been taken before the diagnosis of the calcified mass, it is unknown whether the thrombus had existed for a long time.

In the present case, the creativity of Mother Nature stands out compared with that of human beings.

\section{REFERENCES}

1. Minatoya K, Okabayashi H, Yokota T, Hoover EL. Calcified ball thrombus in the left atrium. Ann Thorac Surg 1996;61: 1513-4.

2. Wrisley D, Giambartolomei A, Lee I, Brownlee W. Left atrial ball thrombus: review of clinical and echocardiographic manifestations with suggestions for management. Am Heart J 1991;121:1784-90.

3. Tarantino MD, Vasu MA, Von Drak TH, Crowe CP, Udall JN Jr. Calcified thrombus in the right atrium: a rare complication of long-term parenteral nutrition in a child. J Pediatr Surg 1991;26:91-3.

4. Sharratt GP, Grover ML, Monro JL. Calcified left atrial myxoma with floppy mitral valve. Br Heart J 1979;42:608-10. 